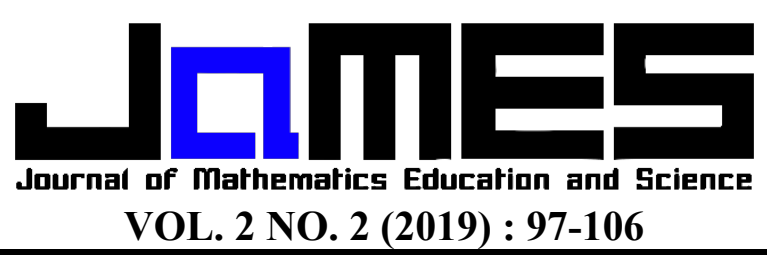

p-ISSN: 2621-1203 | https://doi.org/10.32665/james.v2i2.102

e-ISSN: 2621-1211

\title{
PELEVELAN MODEL MENTAL SISWA DALAM MEMAHAMI PENGGUNAAN KONSEP TEOREMA PYTHAGORAS PADA SISWA SMP
}

\author{
Ninda Sintyah Rachmawati ${ }^{1}$, Junarti ${ }^{2}$, Anita Dewi Utami ${ }^{3}$ \\ IKIP PGRI Bojonegoro, nindacintya13@gmail.com ${ }^{1}$ \\ IKIP PGRI Bojonegoro, junarti@ikippgribojonegoro.ac.id ${ }^{2}$ \\ IKIP PGRI Bojonegoro, anita_dewi@ikippgribojonegoro.ac.id ${ }^{3}$ \\ Received : 18 Juli 2019, Revised : 10 Oktober 2019, Accepted : 11 Oktober 2019 \\ (C) Mathematics Education Unugiri 2019
}

\begin{abstract}
A domain of learning, understanding is an absolute prerequisite for improving cognitive abilities. Leveling the mental model of students is one way in which a teacher can review the extent to which students understand based on their respective levels. The purpose of this study was to describe the six degrees of student's mental models in understanding the concept of using the Pythagoras theorem in junior high school students. The method used in this study is a qualitative research method. The subjects in this study amounted to 61 students who were a combination of 30 students of class VIII A and 31 students of class VIII B. The two classes of subjects were taken so that the six levels of the mental model were founded. The sixty-one items test questions were given. Each of the representatives of mental models who found the criteria was selected, namely two students to be interviewed so that 12 students were interview respondents. To ensure the validity of the data, researchers analyzed the data in two ways, namely data source triangulation and method triangulation. The results of the study showed a description of each level of the student's mental model in understanding the concept of using the Pythagoras theorem.
\end{abstract}

Keywords: Conceptual Understanding, Mental Model, Pythagoras

\begin{abstract}
Abstrak
Suatu domain belajar, pemahaman merupakan prasyaratan mutlak untuk meningkatkan kemampuan kognitif. Pelevelan model mental siswa merupakan salah satu cara dimana seorang pengajar dapat meninjau sejauh manakah pemahaman siswa berdasarkan tingkatan masing - masing. Tujuan penelitian ini adalah untuk mendeskripsikan enam level model mental siswa dalam memahami konsep penggunaan teorema pythagoras pada siswa SMP. Metode yang digunakan dalam penelitian ini adalah metode penelitian kualitatif. Subjek dalam penelitian ini berjumlah 61 siswa yang merupakan gabungan dari 30 siswa kelas VIII A dan 31 siswa kelas VIII B. Dua kelas subjek tersebut diambil agar terpenuhi keenam level model mental. Keenam puluh satu subjek tersebut diberikan soal tes, kemudian dipilih masing - masing dari perwakilan model mental yang telah memenuhi kriteria yaitu 2 siswa untuk diwawancarai. Sehingga terdapat 12 siswa yang menjadi responden wawancara. Untuk memastikan kevalidan data, peneliti menganalisis data dengan dua cara yaitu triangulasi sumber data dan triangulasi metode. Hasil penelitian menunjukkan deskripsi masing - masing level model mental siswa dalam memahami konsep penggunaan teorema pythagoras.
\end{abstract}

Kata kunci: Pemahaman Konsep, Model Mental, Pythagoras

\section{Pendahuluan}

Suatu domain belajar, pemahaman merupakan prasyaratan mutlak untuk meningkatkan kemampuan kognitif [1]. Pemahaman terhadap suatu konsep yang lebih tinggi akan sulit didapatkan jika pemahaman sebelumnya atau pemahaman dasar belum didapatkan. Menurut pendapat Firman [2] seorang siswa dikatakan telah memahami suatu konsep jika memiliki kemampuan untuk menangkap makna dari informasi yang diterima berupa: (1) menafsirkan bagan, diagram, atau 
grafik, (2) menerjemahkan suatu pernyataan verbal kedalam formula matematis, (3) memprediksi berdasarkan kecenderungan tertentu (interpolasi dan eksplorasi), (4) mengungkapkan suatu konsep dengan kata kata sendiri. Sedangkan menurut Sagala [3] pemahaman konsep matematika merupakan kemampuan melakukan kegiatan mental berbentuk aksi (actions), proses (processes), obyek (objects) dan skema (schema) ketika mengkontruksi konsep itu serta kemampuan menghafal maupun menarik kesimpulan dari aturan-aturan yang spesifik menjadi hubungan matematis yang lebih umum.

Berdasarkan pendapat para ahli di atas, tetap tidak dapat dikesampingkan bahwa level pemahaman siswa pun berbeda - beda. Mulai dari dasar, menengah, hingga atas. Pelevelan sendiri adalah tataran atau hal yang digunakan untuk mengukur ketinggian atau tingkatan tertentu dengan batasan - batasan tertentu. Level pemahaman siswa disini dapat diukur dari berbagai hal, salah satunya adalah model mental.

Selaras dengan pendapat Sagala [3] pemahaman konsep matematika merupakan kemampuan melakukan kegiatan mental. Mental itu sendiri terdiri dari beberapa model. Sebagaimana dengan banyaknya penelitian mengenai model - model mental. Menurut Kamus Besar Bahasa Indonesia (KBBI) model adalah pola (contoh, acuan, ragam, dsb) dari sesuatu yang akan dibuat atau dihasilkan. Sedangkan mental adalah hal yang bersangkutan dengan batin dan watak manusia, yang bukan bersifat badan atau tenaga yakni bukan hanya pembangunan fisik yang diperhatikan melainkan juga pembangunan. Menurut Sange [4] model mental merupakan gambaran internal seseorang dalam berpikir serta gambaran yang membatasi seseorang untuk bertindak. Ide-ide dalam pikiran pembelajar yang digunakan untuk menggambarkan, menjelaskan, dan memprediksi sebuah fenomena dinamakan model mental [5][6]. Sedangkan menurut Chittelborough [7] model mental adalah representasi pribadi mental seseorang terhadap suatu ide atau konsep. Model mental dapat digambarkan sebagai model konseptual, representasi mental/ internal, gambaran mental, proses mental, suatu konstruksi yang tidak dapat diamati, dan representasi kognitif pribadi. Model mental dapat menjadi salah satu indikasi dapat diketahuinya tingkat pemahaman siswa. Sehingga dapat disimpulkan bahwa model mental adalah pola dimana manusia berwatak dalam menghasilkan atau membuat sesuatu.

Penelitian model mental dapat ditemukan dalam banyak kajian, di antaranya kajian psikologi kognitif. Psikologi kognitif merupakan sebuah bidang studi tentang bagaimana manusia memahami, belajar, mengingat, dan berpikir tentang suatu informasi [8]. Penelitian model mental juga terdapat dalam kajian science. Seperti pendapat peneliti dalam kajian fisika, Susanti \& Joko [9] bahwa model mental dapat menginformasikan tentang bagaimana seseorang memahami sistem fisis, seperti perilaku objek di dalam hukum - hukum fisika. Salah satu hukum fisika yang erat aplikasinya dengan kehidupan sehari - hari adalah Hukum Newton tentang gerak. Menurut Lehrer [10] belajar science (khususnya Fisika) adalah untuk mengkontruksi, merevisi, dan melakukan justifikasi model mental yang dibangun sendiri, tidak hanya mengadaptasi model mental yang dipaksakan oleh orang lain dan diterima begitu saja.

Selain banyak ditemukannya penelitian model mental pada beberapa kajian, penelitian model mental juga mempunyai beberapa level yang telah diteliti oleh peneliti terdahulu. Pelevelan tersebut terbagi menjadi beberapa tingkatan tertentu sesuai dengan hasil dari tiap - tiap peneliti. Seperti Barsalou [11] yang membagi level model mental menjadi dua berdasarkan level karakteristik model mental yaitu model mental struktural dan model mental konseptual. Kemudian Vosniadou dan Brewer [12] yang melevelkan model mental menjadi tiga, yaitu model mental inisial, model mental sintesis, dan model mental formal. Adapun Park dan Light [13] melevelkan model mental menjadi 5 tingkatan, yaitu model mental awal tak berbentuk atau tidak jelas, model mental 
intermediate 1, model mental intermediate 2, model mental intermediate 3 , dan target model mental.

Berbeda dengan banyaknya penelitian model mental pada materi science, ternyata pada matematika hanya ada beberapa penelitian model mental saja. Diantaranya adalah penelitian model mental siswa terhadap pemahaman tentang konsep bilangan bulat negatif oleh Bofferding [14]. Bofferding menemukan lima model mental siswa terhadap pemahamannya mengenai bilangan bulat, yaitu model mental initial, transisi 1 , model mental sintetik, transisi 2, serta model mental formal. Kemudian penelitian tersebut dikembangkan oleh Utami, dkk [15] menjadi 6 model mental dengan menambahkan pra-inisial sebelum model mental inisial. Sehingga hasil penelitian tersebut menunjukkan ada enam level model mental siswa; yaitu model mental pra-inisial, inisial, transisi 1, sintesis, transisi 2, dan formal. Pemahaman konsep penggunaan teorema pythagoras adalah salah satu topik menarik yang dapat dikaji pada pelevelan model mental. Penelitian oleh Rista [17] bahwa menanamkan konsep Pythagoras melalui metode pemahaman konsep dengan cara perolehan konsep dirasa adalah metode yang paling tepat untuk menyelesaikan permasalahan yang berkaitan dengan bangun datar. Hal ini menunjukkan bahwa konsep pythagoras dapat menjadi salah satu alternatif yang sangat membantu dalam meningkatan pemahaman terhadap materi lain.

Meski begitu, penggunaan konsep teorema pythagoras sendiri masih dirasa sulit oleh siswa. Pemahaman siswa tentang konsep segitiga karena luas persegi dan luas segitiga siku-siku dalam menemukan teorema pythagoras masih rendah. Seperti penelitian oleh Muncarno [18] yang menyimpulkan bahwa siswa mengalami kesulitan dalam memahami soal disebabkan karena siswa kurang cermat dalam membaca dan memahami kalimat demi kalimat, mengenai hal yang diketahui, ditanyakan, serta cara menyelesaikan soal secara tepat. Selain itu, subjek mengaku lupa dengan materi teorema pythagoras dan rumus luas bangun datar. Hal tersebut sejalan dengan hasil penelitian Ruspiani [19] dan Lestari [20] masing-masing mengungkapkan bahwa kemampuan terendah siswa ada pada kemampuan koneksi antar topik matematika. Selain itu, menurut Budiyono [21] jenis-jenis kesalahan yang dilakukan siswa dalam menyelesaikan soal matematika yaitu kesalahan konsep, meliputi (1) kesalahan menentukan teorema atau rumus untuk menjawab masalah, (2) penggunaan rumus atau teorema oleh siswa tidak sesuai dengan kondisi prasyarat berlakunya rumus tersebut. Adapun penelitian oleh Ardhianingsih [22] masih ada keterbatasan dari banyak siswa untuk menentukan syarat cukup dan perlu dalam penjelasan konsep - konsep bangun datar dan bangun ruang.

Berdasarkan hasil dari beberapa penelitian di atas, perlu diadakan penelitian lebih lanjut terkait hal tersebut untuk mengetahui pelevelan model mental siswa dalam memahami konsep teorema pythagoras. Maka penelitian mengenai pelevelan model mental siswa dalam memahami konsep penggunaan teorema pythagoras ini termasuk hal yang penting untuk dikaji lebih dalam. Sehingga melalui perbedaan - perbedaan tingkat pemahaman siswa dalam memahami konsep penggunaan teorema pythagoras tersebut, akan ada pembelajaran dan pengetahuan yang didapatkan dari pendeskripsian tingkat level mereka melalui penelitian pelevelan model mental. Untuk itu peneliti akan melakukan penelitian tentang pelevelan model mental siswa dalam memahami konsep penggunaan theorema pythagoras.

\section{Metode Penelitian}

Penelitian ini adalah penelitian kualitatif. Instrumen dalam penelitian ini adalah soal tes dan pedoman wawancara. Soal tes terdiri dari 6 soal dengan masing - masing soal mempunyai nilai tingkatan sesuai dengan levelnya. Subjek dalam penelitian ini berjumlah 61 siswa yang terdiri dari 30 siswa kelas VIII A dan 31 siswa dari kelas VIIIB. Alasan pemilihan 
subjek dari dua kelas tersebut ialah agar terpenuhi keseluruhan model mental. Kemudian dari 61 siswa tersebut akan diambil kembali 12 siswa yang memenuhi standar kriteria pelevelan model mental dan memiliki kemampuan komunikasi yang baik dan aktif. Adapun indikator yang diambil adalah seperti yang ditunjukkan oleh Tabel 1.

Tabel 1. Indikator 6 Level Model Mental Dalam Memahami Konsep Penggunaan Teorema Pythagoras Adopsi Dari Utami, A. D [15]

\begin{tabular}{cc}
\hline Model Mental & Indikator \\
\hline Pra Inisial & $\begin{array}{c}\text { Anak sama sekali tidak mengetahui } \\
\text { rumus yang berkaitan dengan } \\
\text { konsep penggunaan teorema } \\
\text { phytagoras. }\end{array}$ \\
\hline Inisial & Anak dapat memahami rumus yang \\
& berkaitan dengan segitiga dan \\
& segiempat yang ada pada konsep \\
& penggunaan teorema phytagoras. \\
\hline & Anak telah dapat memahami rumus \\
& yang berkaitan dengan segitiga dan \\
Transisi I & segiempat yang ada pada konsep \\
& penggunaan teorema phytagoras, \\
& namun mereka tidak konsisten \\
& dalam pengerjaannya. \\
\hline Sintesis & Anak sudah dapat memahami \\
& dengan baik dan konsisten benar \\
& dalam mengerjakan materi yang \\
& berkaitan dengan segitiga dan \\
& persegi. Anak juga mulai \\
& memahami materi tripel \\
& phytagoras.
\end{tabular}

\begin{tabular}{cc}
\hline Transisi II & $\begin{array}{c}\text { Anak belum dapat konsisten dalam } \\
\text { memahami dan mengerjakan soal } \\
\text { yang berkaitan dengan tripel } \\
\text { phytagoras. }\end{array}$ \\
\hline Formal & $\begin{array}{c}\text { Anak sudah memahami dengan } \\
\text { baik dan benar serta konsisten } \\
\text { dalam pengerjaan materi yang } \\
\text { berkaitan dengan segitiga, persegi, } \\
\text { dan tripel phytagoras. }\end{array}$ \\
\hline
\end{tabular}

Berdasarkan jawaban 61 siswa yang telah dikelompokkan dalam enam level model mental seperti dalam indikator tabel 1 di atas, berikut distribusi jumlah jawaban siswa yang ditunjukkan Tabel 2.
Tabel 2. Jumlah Siswa Pada Masing - Masing Level Model Mental

\begin{tabular}{ccc}
\hline No & Model Mental & Jumlah Siswa \\
\hline 1 & Pra - Inisial & 2 siswa \\
\hline 2 & Inisial & 9 siswa \\
\hline 3 & Transisi I & 8 siswa \\
\hline 4 & Sintesis & 10 siswa \\
\hline 5 & Transisi II & 20 siswa \\
\hline 6 & Formal & 12 siswa \\
\hline
\end{tabular}

Berdasarkan jumlah siswa pada masing masing level yang ditunjukkan oleh tabel 2, dipilih dua orang untuk diwawancarai. Pemilihan subjek untuk diwawancarai didasarkan pada kemampuan komunikasi siswa.

\section{Hasil dan Pembahasan}

3.1. Analisis Data

Analisis data dilakukan oleh peneliti setelah memperoleh data penelitian dari melakukan tes dan wawancara. Sebelum mengadakan tes, peneliti telah lebih dahulu mengadakan observasi untuk mengamati sejauh mana pengetahuan yang telah dimiliki siswa. Kemudian pada hari berikutnya peneliti melakukan tes dimana sebelumnya peneliti telah menyiapkan soal kemudian melakukan validasi soal dan validasi pedoman wawancara. Setelah hasil tes didapatkan, peneliti menimbang dan memilih 12 subjek terpilih untuk diwawancara. Setiap wawancara dalam penelitian ini direkam oleh peneliti dalam bentuk voice record. Voice record yang telah terkumpul kemudian dianalisis dengan cermat dengan memperhatikan hubungan antara hasil tes dan hasil wawancara. Kemudian dari situlah peneliti berhasil menemukan data dalam pengelompokan enam level model mental terhadap pemamahaman konsep penggunaan teorema pythagoras.

\subsection{Hasil Penelitian}

Berikut adalah keenam subjek pada enam jenis level model mental untuk penjelasan masing - masing siswa dalam memahami penggunaan konsep teorema pythtagoras.

1. Model Mental Pra Inisial

S1 tidak ada pemahaman sama sekali mengenai konsep penggunaan teorema 
pythagoras. Hal ini dapat dibuktikan dengan jawaban hasil tes S1 yang tidak dapat menjawab soal tes yang diberikan oleh peneliti dengan benar. Jawaban S1 mengatakan bahwa untuk mencari diagonal PR harus mengalikan panjang PQ dengan panjang PR. Jawaban S1 tidak dibenarkan sebab yang ditanyakan adalah panjang diagonal, sedangkan jawaban yang diberikan subjek S1 adalah rumus dari luas persegi panjang. Hal ini dapat ditunjukkan oleh gambar 1 berikut ini :

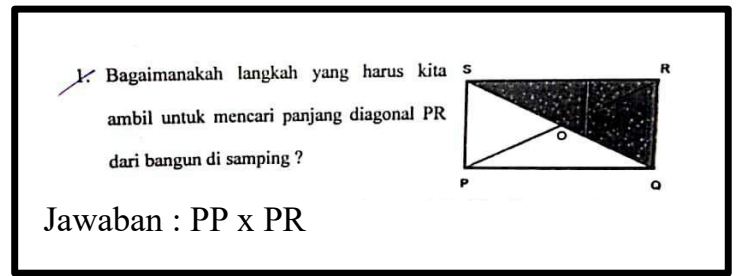

\section{Gambar 1. Jawaban Model Mental Pra Inisial S1}

Berdasarkan jawaban diatas dan hasil wawancara, terlihat bahwa S1 belum memahami penggunaan konsep teorema pythagoras, S1 menyamakan pecarian diagonal pada persegi PQRS dalam soal tersebut sama dengan pencarian luas persegi panjang.

\section{Model Mental Inisial}

Siswa pada level model mental ini sudah memahami penggunaan konsep teorema pythagoras. Namun masih belum sempurna ketika dimasukkan langsung dalam praktek pengerjaan soal. Seperti yang terlihat pada gambar jawaban di awah ini, bahwa S2 lebih fokus pada pencarian luas segitiga saja tanpa harus mencari lebih dulu panjang dari tinggi dengan menggunakan rumus dari teorema phytagoras.

Berdasarkan soal dan jawaban pada gambar 2 menunjukkan bahwa jawaban dari S2 nomor 1 dan 2 benar, namun S2 mengatakan bahwa untuk mencari luas segitiga yang belum diketahui berapa tingginya adalah dengan memasukkan semua nomor yang diketahui agar masuk

dalam perhitungan rumus. Padahal seharusnya yang benar ialah agar mencari panjang dari tinggi terlebih dahulu.

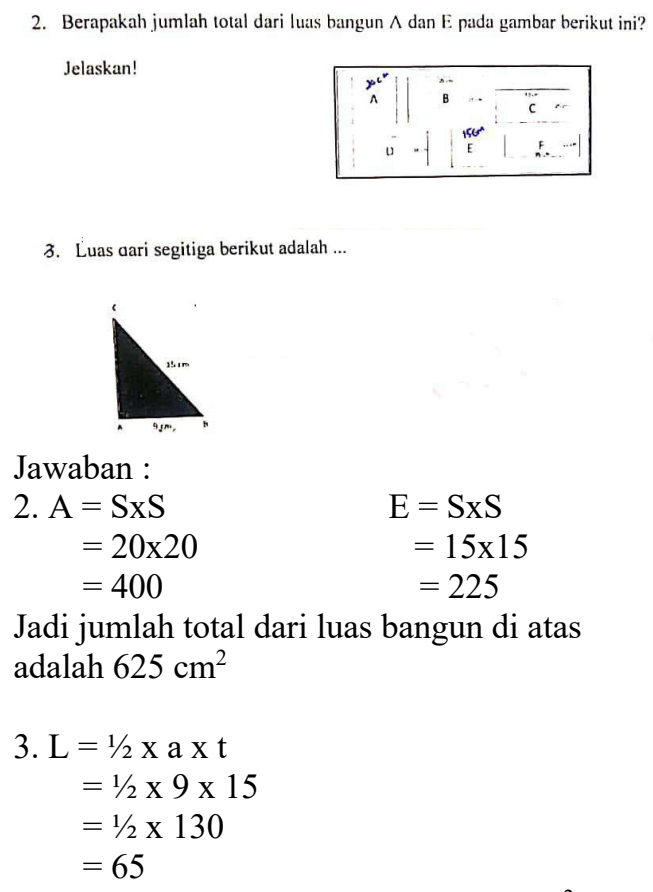

2. Berapakah jumlah total dari luals bangun $\Lambda$ dan E pada gambar berikut ini? Jelaskan!

3. Luas aari segitiga berikut adalah ...

Jawaban :

$$
\text { 2. } \begin{array}{rlrl}
\mathrm{A} & =\mathrm{S} \times \mathrm{S} & \mathrm{E} & =\mathrm{S} \times \mathrm{S} \\
& =20 \times 20 & & =15 \times 15
\end{array}
$$$$
=400
$$$$
=225
$$

Jadi jumlah total dari luas bangun di atas adalah $625 \mathrm{~cm}^{2}$

$$
\text { 3. } \begin{aligned}
\mathrm{L} & =1 / 2 \times \mathrm{a} \times \mathrm{t} \\
& =1 / 2 \times 9 \times 15 \\
& =1 / 2 \times 130
\end{aligned}
$$$$
=65
$$

Jadi luas segitiga tersebut adalah $65 \mathrm{~cm}^{2}$

Gambar 2. Jawaban Model Mental Inisial S2

\section{Model Mental Transisi 1}

Siswa pada level ini sebenarnya sudah memahami dan dapat mengerjakan soal mengenai teorema pythagoras. Hanya saja S3 belum bisa konsisten benar dalam pengerjaannya. S3 masih salah dalam meghitung penjumlahan dua bilangan yang dikuadratkan. Hal ini dapat ditunjukkan oleh gambar 3 berikut ini :

$$
\begin{aligned}
& \text { 4. Sebuah persegi panjang memiliki panjang } 16 \mathrm{~cm} \text { dan lebar } 12 \mathrm{~cm} \text {. Panjang } \\
& \text { diagonal persegi panjang tersebut adalah... } \\
& =\sqrt{784}
\end{aligned}
$$

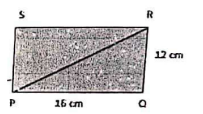

Gambar 3. Jawaban Model Mental Transisi I S3 
Berdasarkan soal dan jawaban pada gambar 3 , kondisi seperti ini peneliti memasukkan S3 berada pada level model mental transisi I. Sebab ketika peneliti menanyakan kepada S3 mengapa menjumlahkan lebih dahulu kedua bilangan yang berpangkat, S3 hanya menjawab agar lebih cepat saja. Meski S3 menuliskan rumus yang benar, akan tetapi salah dalam pengerjaan, berarti pembenaran jawaban tidak ada di sini.

\section{Model Mental Sintesis.}

Siswa pada level model mental ini sudah memahami dan dapat mengerjakan soal mengenai teorema phytagoras. Bahkan melalui percakapan wawancara yang ditanyakan oleh peneliti, S4 sudah mulai memahami materi tripel phytagoras. Terbukti sebelum mengerjakan soal nomor 5 yaitu nomor $1,2,3$, dan 4 sudah benar semuanya. Jawaban nomor 5 pun menunjukkan bahwa S3 bisa memahami rumus teorema pythaagoras dengan baik. Hanya dalam pengerjaan masih salah memahami permintaan soal dan jawaban yang seharusya diberikan. Hal ini dapat ditunjukkan oleh gambar 4 berikut ini :

5. Panjang $\mathrm{AD}$ pada gambar berikut adalah ?

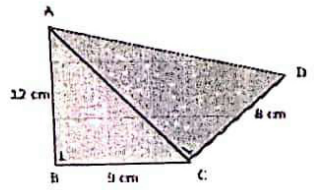

Jawaban :

$$
\begin{aligned}
\mathrm{AD} & =\sqrt{A R^{2}+B C^{2}} \\
& =\sqrt{12^{2}+9^{2}} \\
& =\sqrt{144+81} \\
& =\sqrt{225} \\
& =15 \mathrm{~cm}
\end{aligned}
$$

Gambar 4. Jawaban Model Mental Sintetis S4

Berdasarkan jawaban di atas menunjukkan bahwa S4 sudah dapat memahami dan mengerjakan materi konsep penggunaan teorema phytagoras dan mulai memahami materi tripel phytagoras.
5. Model Mental Transisi 2

Siswa pada level model mental ini sudah dapat memahami rumus yang berkaitan dengan segitiga dan segiempat yang ada pada konsep penggunaan teorema phytagoras, sebab soal - soal pada nomor sebelumnya dapat dikerjakan dengan baik. Siswa sudah memahami materi tripel phytagoras, hanya saja kurang konsisten dalam pengerjaannya. Hal ini dapat ditunjukkan oleh gambar 5 berikut ini :

6. Dari tiga bilangan berikut, yang merupakan tripel pythagoras adalah?

Jelaskan!

a. $9,13,15$

b. $7,12,15$

c. $10,24,25$

d. $8,15,17$

Jawaban : a. 9, 3, 15 (ganjil)

Gambar 5. Jawaban Model Mental Transisi II S5

Berdasarkan jawaban di atas terlihat benar bahwa S5 sudah memahami konsep phytagoras dan tripel phytagoras, meski nomor 6 salah akan tetapi jawaban untuk nomor 1 sampai 5 yang benar sudah membuktikan bahwa S5 berada pada level model mental transisi 2. Terbukti saat wawancara S5 hanya menebak dengan hafalan angka tripel phytagoras yang diketahui, padahal angka pada tripel phytagoras yang diketahui adalah salah.

6. Level Model Mental Formal.

Siswa pada level model mental ini sudah dapat memahami dengan baik dan benar serta konsisten dalam pengerjaan materi yang berkaitan dengan segitiga, persegi, dan tripel phytagoras. Hal ini dapat ditunjukkan oleh gambar 6 .

Berdasarkan jawaban pada gambar 6 , dapat peneliti simpulkan bahwa S6 sudah dapat memahami dan mengerjakan semua soal materi teorema pythagoras. Ketika peneliti bertanya lebih detail tentang jawabannya, S6 juga dapat menjelaskan dengan baik dan sangat jelas. 
6. Dari tiga bilangan berikut, yang merupakan tripel pythagoras adalah?

Jelaskan!

a. $9,13,15$

b. $7,12,15$

c. $10,24,25$

d. $8,15,17$

Jawaban :
a. $15^{2}=13^{2}+9^{2}$
$=169+81$
$225 \neq 250$
b. $15^{2}=7^{2}+12^{2}$
$=49+144$
$225 \neq 193$
c. $25^{2}=24^{2}+10^{2}$
$=576+100$
$625 \neq 676$
d. $\quad 17^{2}=15^{2}+8^{2}$
$=225+64$
$289=289$

Jadi bilangan yang merupakan tripel phytagoras adalah d. 8, 15, 17

Gambar 6. Jawaban Model Mental Formal S6

Berdasarkan hasil penelitian Utami, dkk [15] menunjukkan ada enam level model mental siswa dalam memahami konsep bilangan bulat yaitu : model mental pra inisial, model mental inisial, model mental transisi 1, model mental sintetis, model mental transisi 2, dan yang terakhir adalah model mental formal. Utami, dkk [15] mengembangkan enam level model mental tersebut berdasarkan pelevelan model mental Bofferding [14] yang membagi lima level model mental siswa dalam memahami konsep bilangan bulat dengan menambahkan model mental pra-inisial. Pada penelitian ini, peneliti melakukan penelitian dengan berpedoman pada enam level model mental yang telah dijabarkan oleh Utami, dkk [15] pada materi teorema pythagoras. Berikut penjabaran level model mental dalam memahami penggunaan konsep teorema pythagoras pada Tabel 3.

Model mental pra inisial diberikan kepada siswa yang sama sekali tidak mengetahui rumus yang berkaitan dengan konsep penggunaan teorema phytagoras, rumus - rumus segitiga, dan segiempat yang berkaitan dengan konsep pengggunaan teorema phytagoras. Sejalan dengan Utami [16] yang menyatakan bahwa model mental pra-inisial dalam memahami konsep fungsi dapat dilihat ketika mahasiswa belum memahami konsep relasi dengan baik dan belum mampu menyatakan bahwa suatu relasi bukan merupakan fungsi.

\section{Gambar 7. Level Model Mental Siswa Dalam Memahami Konsep Penggunaan Teorema Phytagoras.}

\begin{tabular}{|c|c|}
\hline $\begin{array}{c}\text { Model } \\
\text { Mental } \\
\end{array}$ & Penjabaran Level \\
\hline Pra Initial & $\begin{array}{l}\text { siswa sama sekali tidak memahami } \\
\text { rumus yang berkaitan dengan konsep } \\
\text { penggunaan teorema phytagoras. }\end{array}$ \\
\hline Initial & $\begin{array}{c}\text { siswa sudah memahami rumus yang } \\
\text { berkaitan dengan konsep penggunaan } \\
\text { teorema phytagoras }\end{array}$ \\
\hline Transisi 1 & $\begin{array}{l}\text { siswa sudah memahami rumus yang } \\
\text { berkaitan dengan konsep penggunaan } \\
\text { teorema phytagoras namun belum } \\
\text { konsisten dalam pengerjaannya. }\end{array}$ \\
\hline Sintetis & $\begin{array}{c}\text { siswa sudah konsisten benar dalam } \\
\text { mengerjakan materi yang berkaitan } \\
\text { dengan teorema phytagoras dan sudah } \\
\text { mulai memahami materi tripel } \\
\text { phytagoras. }\end{array}$ \\
\hline Transisi 2 & $\begin{array}{c}\text { siswa belum konsisten dalam } \\
\text { memahami dan mengerjakan soal yang } \\
\text { berkaitan denga tripel phytagoras. }\end{array}$ \\
\hline Formal & $\begin{array}{c}\text { siswa sudah memahami dengan baik } \\
\text { dan benar serta konsisten dalam } \\
\text { pengerjaan materi yang berkaitan } \\
\text { dengan segitiga, persegi, dan trpel } \\
\text { phytagoras. }\end{array}$ \\
\hline
\end{tabular}

Model mental inisial diberikan kepada siswa yang sudah dapat memahami rumus segitiga dan segiempat yang sedikit menyinggung pada konsep penggunaan teorema phytagoras. Setelah peneliti amati bahwa salah satu subjek terpilih yang peneliti jadikan sebagai perwakilan dari sembilan anak tersebut, ternyata masing - masing dari mereka hanya sebatas memahami rumus yang berkaitan dengan segitiga dan segiempat yang ada pada konsep penggunaan teorema phytagoras. Ketika dihadapkan dengan soal yang lebih berkembang, ia akan merasa kesulitan dan tidak dapat menyelesaikan. Sesuai dengan pernyataan 
Vula, dkk [23] bahwa siswa cenderung menyelesaikan satu operasi aritmatika saja.

Model mental transisi 1 diberikan kepada siswa yang sudah dapat memahami rumus segitiga dan segiempat yang berkaitan dengan konsep penggunaan teorema phytagoras, akan tetapi mereka masih belum bisa konsisten dalam pengerjaannya. Setelah peneliti amati bahwa salah satu subjek terpilih yang peneliti jadikan sebagai perwakilan dari delapan anak tersebut, ternyata masing masing dari mereka sebenarnya sudah memahami materi dan rumus segitiga maupun segiempat yang berkaitan dengan konsep penggunaan teorema phytagoras akan tetapi mereka masih belum bisa konsisten benar dalam pengerjaannya. Kekonsistensian ini memang dirasa sulit bagi mereka yang berada pada level transisi 1 dan harus dibiasakan untuk terus berlatih, meski yang dipahami baru sebatas materi rumus segitiga dan segiempat yang berkaitan dengan konsep penggunaan teorema phytagoras. Tidak hanya dalam level ini, Maya [24] menyatakan bahwa konsisten belajar setiap hari untuk objek-objek pelajaran yang memang dianggap penting adalah cara ideal untuk membuat proses belajar menjadi lebih mendalam.

Model mental sintetis diberikan kepada siswa yang sudah dapat memahami rumus segitiga dan segiempat yang berkaitan dengan konsep penggunaan teorema phytagoras dengan baik, konsisten, dan benar bahkan mereka mulai mengerjakan materi tripel phytagoras. Memulainya mereka dalam pengerjaan atau pemahaman tentang materi tripel phytagoras ini sejalan dengan pendapat Krathwohl [25] bahwa peserta didik dapat menganalisis informasi yang masuk dan membagi-bagi atau menstrukturkan informasi kedalam bagian yang lebih kecil untuk mengenali pola atau hubungannya. Berdasarkan pendapat tersebut, dapat diketahui dalam pengerjaan rumus - rumus segitiga dan segiempat yang mengandung konsep penggunaan teorema phytagoras akan membentuk hubungan yang saling berkesinambungan denga materi tripel pythagoras.
Model mental transisi 2 diberikan kepada siswa yang sudah dapat memahami rumus segitiga dan segiempat yang berkaitan dengan konsep penggunaan teorema phytagoras dan memahami materi tripel phytagoras akan tetapi mereka belum konsisten dalam memahami dan mengerjakan soal tripel phytagoras dengan baik dan benar. Setelah peneliti amati bahwa salah satu subjek terpilih yang peneliti jadikan sebagai perwakilan dari delapan anak tersebut, ternyata masing masing dari mereka sebenarnya masih ingat materi tripel phytagoras dan sudah dapat mengerjakannya dengan baik, namun masih ada ketidakkonsistenan dalam pengerjaannya. Oleh karena itu perlu adanya kedisiplinan latihan soal agar siswa terlatih dan merasa lebih teliti serta mudah dalam mengerjakan berbagai macam soal matematika, khususnya materi teorema phytagoras. Sejalan dengan Harjo [26] yang mengatakan bahwa komponen penting dari kedisiplinan harus dirumuskan, jika tidak dirumuskan akan terjadi ketidakkonsistenan antara siswa yang satu dengan siswa yang lain dalam menangkap materi.

Model mental formal diberikan kepada siswa yang sudah dapat memahami rumus segitiga dan segiempat yang berkaitan dengan konsep penggunaan teorema phytagoras, dan materi tripel phytagoras dengan sempurna. Subjek yang berhasil masuk dalam level model mental ini dapat dikatakan sebagai subjek yang sempurna dalam pemahaman dan termasuk subjek yang dapat berfikir tingkat tinggi sebab dapat memecahkan masalah (soal tes uraian) dengan sempurna. Dewanto dalam Amalia [27] menyatakan bahwa kemampuan berpikir tingkat tinggi adalah suatu kapasitas diatas informasi yang diberikan, dengan sikap yang kritis untuk mengevaluasi, mempunyai kesadaran (awareness) metakognitif dan memiliki kemampuan pemecahan masalah.

\section{Kesimpulan}

Berdasarkan hasil penelitian di atas, dapat disimpulkan bahwa terdapat beberapa level model mental dalam memahami konsep penggunaan teorema pythagoras, yaitu model 
mental pra inisial di mana bentuk model mental pra inisial anak dapat dilihat dari informasi yang dimiliki siswa yang tersimpan dalam memori jangka panjangnya sebelum mereka dihadapkan sebuah konsep tertentu. Siswa sama sekali tidak mengetahui rumus yang berkaitan dengan konsep penggunaan teorema pythagoras, yaitu rumus yang berkaitan dengan segitiga, persegi, dan tripel pythagoras. Kemudian model mental yang kedua adalah model mental initial, dimana siswa sudah dapat memahami rumus yang berkaitan dengan segitiga dan segiempat yang ada pada konsep penggunaan teorema pythagoras. Model mental yang ketiga, ialah model mental transisi I, dimana siswa memang sudah dapat memahami rumus yang berkaitan dengan segitiga dan segiempat yang ada pada konsep penggunaan teorema pythagoras. Namun mereka tidak konsisten dalam pengerjaannya. Mereka masih sering salah dan belum tepat dalam pengerjaan.

Adapun model mental yang keempat ialah model mental sintesis, siswa sudah dapat memahami dengan baik dan konsisten benar dalam mengerjakan materi yang berkaitan dengan segitiga dan persegi. Siswa juga mulai memahami materi tripel phytagoras. Model mental yang kelima adalah model mental transisi II, dimana siswa sudah memahami segala materi yang berkaitan dengan teorema pythagoras namun siswa tidak konsisten dalam memahami dan mengerjakan soal yang berkaitan dengan tripel pythagoras. Dan yang terakhir adalah model mental formal, dimana siswa dapat dikatakan sempurna dalam pemahaman. Sebab dalam model mental ini siswa sudah memahami dengan baik dan benar serta konsisten dalam pengerjaan materi yang berkaitan dengan segitiga, persegi, dan tripel pythagoras.

Berdasarkan hasil penelitian yang didapatkan oleh peneliti, level model mental pra inisial seharusnya tidak ada pada tingkat tersebut yaitu siswa kelas VIII. Sebab sejak awal semester II, siswa SMP kelas VIII sebenarnya sudah mendapatkan pembelajaran dan materi mengenai materi teorema pythagoras. Pada penelitian ini pun ditemukan ada dua siswa yang berada pada level tersebut. Oleh sebab itu, kedepannya mungkin perlu diadakan penelitian lanjutan mengenai apa yang menyebabkan siswa berada pada level tersebut.

\section{Referensi}

[1] Berns dan Erickson, Principles and Standard for School Mathematics, Jurnal Ilmiah Matematika, (2001).

[2] Firman, "Kiat Pendidikan Matematika di Indonesia", Jakarta: Direktorat Jendral Pendidikan Tinggi, (2000).

[3] Sagala, M., "Pembelajaran Keterampilan Membaca Matematika pada Siswa Sekolah Menengah". Bandung: FMIPA Universitas Pendidikan Indonesia, (2016).

[4] Sange, P. M., "The Fifth Discipline. The Art and Practice of the Learninf Organization”, New York : Doubleday Dell Publishing Group, Inc. (2004) 405 pages.

[5] Jansoon, N., Understanding Mental Models of Dilution in Thai Students, International Journal of Environmental \& Science Education. vol.4 no.2, (2009) 147-168.

[6] Wang, C. Y., The Role of Mental Modelling Ability, Content Knowldge, and Mental Models in General Chemistry Students' Understanding about Molecular Polari, Dissertation for the Doctor Degree of Philosophy in the Graduate School of the Univerity of Missouri. Columbia, (2007).

[7] Chittelborough, L., The Role of Mathematical Symbolin Development of Number Conceptualization: The case of the Minus Sign, Philosopical Psuchology, vol.21 no.4, (2007).

[8] Stenberg, Connected Mathematics Project (CMP) Model Based on Presentation Media to the Mathematical Connection Ability of Junior High School Student, Journal of Education and Practice, vol.4 no.4, (2008) 2-4.

[9] Susanti dan Joko, Kemampuan Guru matematika, Calon Guru Matematika, dan 
Siswa dalam Mata Pelajaran Matematika, Tesis PPS IKIP Bandung, (2013).

[10] Lehrer, Identifikasi Kesalahan-Kesalahan yang Diperbuat Siswa Kelas III SMP pada Setiap Aspek Penguasaan Bahan Pelajaran Matematika. Tesis FPS IKIP Malang, (2009)

[11] Barsalou, L. W. "Tutorial essays in cognitive science. Cognitive psychology: An overview for cognitive scientists". Hillsdale, NJ, US: Lawrence Erlbaum Associates, Inc., (1992).

[12] Vosniadou, S. dan Brewer, W. F., Mental Model of The earth: A Study of Conceptual Change in Childood, Cognitive Psychology, vol.24 no.4 (1992) $535-585$.

[13] Park, E.J. dan Light, G., Identifying Atomic Structure as a Rhreshold Concept: Student Mental Models and Troublesomeness, International Journal of Science Education, vol.31 no.2, (2009) 233-258.

[14] Bofferding, L., Negative Integer Understanding: Characterizing First Graders' Mental Models, Journal for Research in Mathematics Education, vol.45 no.2, (2014) 194-245.

[15] Utami, A. D. et al., Six Level Of Primary School Student's Mental Model In Comprehending The Concept Of Integer: A Case In Indonesia Context, International Jurnal Of Instruction, Vol.11 no.4, (2018) $29-44$.

[16] Utami, A. D. et al., Student's Pre-Initial Mental Model: The Case Of Indonesian First-Year Students, International Jurnal Of Instruction, vol.12 no.1, (2019) 1173 1188.

[17] Rista, Koneksi Matematik dalam Pembelajaran Matematika di Sekolah Menengah Pertama. Pythagoras, vol.4 no.1, (2015).

[18] Muncarno, "Penerapan Model Penyelesaian Soal Cerita Dengan Langkah-Langkah Pemecahan Masalah Untuk Meningkatkan Prestasi Belajar Matematika Siswa Kelas I SMP”,
Lampung: LPMP Universitas Lampung, (2008).

[19] Ruspiani, Mengembangkan Kemampuan Berpikir Kristis Mahasiswa Pendidikan Matematika Sebagai Calon Pendidik Karaketer Bangsa Melalui Pemecahan Masalah, Jurnal Ilmiah, vol.4 no.4, (2000).

[20] Lestari, Profil Berpikir Kritis Siswa SMP dalam Pemecahan Masalah Matematika ditinjau dari Gaya Kognitif. Tesis Program Sarjana Universitas Tadulako, (2012).

[21] Budiyono, "Kesalahan Mengerjakan Soal Cerita dalam Pembelajaran Matematika. Paedagogia”, (2008).

[22] Ardhianingsih, "Pengembangan Pembelajaran Matematika”. Semarang: Universitas Negeri Semarang, (2010).

[23] Vula, E., Avdyli, R., Berisha, V., Saqipi, B., dan Elezi, S., The Impact of Metacognitive Strategies and SelfRegulating Processes of Solving Math Word Problems, International Electronic Journal of Elementery Education, vol.10 no.1, (2017) 49-59.

[24] Maya, "Penelitian Tindakan Kelas sebagai Sarana Pengembangan Keprofesionalan Guru dan Calon Guru. Teach Mathematics. Educational Studies in Mathematics", Malang: Bayu Media, vol.47 no.2, (2013).

[25] Krathwohl, "A Revision of Blomm's Taxonomy: an Overview", Teori into Practice, (2002).

[26] Harjo, H. "Berbagai Pendekatan dalam Proses Belajar dan Mengajar Matematika”. Jakarta: PT. Bumi Warna Media, (2014).

[27] Amalia, R., Penerapan Model Pembelajaran Pembuktian Untuk Meningkatkan Kemampuan Berpikir Matematis Tingkat Tinggi Siswa SMA, Skripsi Universitas Pendidikan Indonesia, Bandung (2013). 